\title{
Laboratory investigations of arcing on W-coated graphite components
}

\author{
M. Laux ${ }^{b *}$, P. Siemroth ${ }^{c}$, M. Marx ${ }^{c}$, R. Neu ${ }^{a}$, V. Rohde ${ }^{a}$, M. Balden ${ }^{a}$ and N. Endstrasser ${ }^{a}$ \\ ${ }^{a}$ Max-Planck-Institut für Plasmaphysik,EURATOM Association, Boltzmannstr.2, D-85748 Garching \\ ${ }^{b}$ Teilinstitut Greifswald, Wendelsteinstr.1, D-17491 Greifswald, Germany
}

${ }^{c}$ Arc Precision Sources, Coatings and Analysis GmbH, Bahnhofstr.1, D-15745, Wildau, Germany

\begin{abstract}
Results of laboratory experiments of arcing on graphite tiles coated by a W-layer are reported. The samples have been taken from coated tiles manufactured for ASDEX Upgrade (AUG). The motion of the arcs was observed by high-speed cameras. Additionally, sample plates have been exposed to collect macro-particles emitted by the arc. The eroded surfaces of the cathodes were investigated after experiment to characterize surface changes, tracks, and redeposited particles. On the cathode strongly radiating immobile spots are observed by the cameras acting as sources of numerous macro-particles. At the surface large holes (diameter $17 \mu \mathrm{m})$ are found that perforate the W-layer and extend into the graphite bulk. Subsequent arcs tend to locate at the pre-existing holes. Hence, locally the W-coating is quickly and effectively broken, the $\mathrm{W}$ erosion is enhanced as compared to bulk $\mathrm{W}$, and carbon is locally liberated despite the existence of an undamaged $\mathrm{W}$-coating outside the arcing region.
\end{abstract}

PACS: $\quad$ 52.27.Lw, 52.40.Hf, 52.80.Mg

PSI-20 keywords: $\quad$ Arcing, Coating, Dust, Erosion\&Deposition, Tungsten 
*Corresponding author address: Wendelsteinstr.1, D-17491 Greifswald, Germany

*Corresponding author E-mail: michael.laux@ipp.mpg.de

Presenting author: Michael Laux

Presenting author e-mail: michael.laux@ipp.mpg.de 


\section{Introduction}

Arcing of PFCs in fusion devices is one of the basic processes of plasma surface interaction. Traces of arcs have been repeatedly recognized since limiters, divertors, and other plasma facing components (PFCs) underwent regular inspections [1, 2]. The arc phenomenon, underlying physics, and application of arcs are summarized in $[3,4]$.

Early experimental investigations offering temporal and spatial resolution demonstrated that arcs are predominantly ignited during unstable events in the imbedding discharge and their tracks are distributed non-homogeneously over the inner surface of the machine (see again $[1,2])$. Therefore, it was assessed that for a calm discharge the competing sputtering remains to be the dominant erosion process [5] and the interest in arcing abated. However, three new developments changed the situation again and have the potential to arouse new interest in arcing on PFCs: i) the favored tokamak discharges are of ELMy H-mode type having genuine instabilities, ii) for coated materials (like e.g. W-covered graphite) the maintenance of the coverage seems to be of greater importance than the overall erosion rate, and iii) rising attention is paid for the role of dust in fusion machines.

Shortly after the first exposures of W-coated PFCs numerous arc tracks have been identified, investigated, and reported $[6,7,8]$. Simultaneously, solidified molten particles made of W appeared in the dust collected in ASDEX Upgrade (AUG) as a machine equipped with W-coatings [9]. Unfortunately, the physical models developed for arcing are barely applicable to a coated cathode material because of the basic differences in heat and current transport into such a cathode.

To improve the knowledge about arcing of W-coated carbon PFCs dedicated laboratory experiments have been carried out by running vacuum arcs on such PFC-material. Vacuum arcs are relevant physics models for the arcing at PFCs in SOL-plasmas because of the autonomy of the self-produced cathode plasma. Results of these investigations [10] are reported and discussed in this contribution.

\section{Experimental set-up}


The all metal vacuum chamber is a 4-way cross having a pumping port, two ports for target holder, a current feed throughs, an ignition electrode, and a port with a large window (DN100CF) for target observation. To the left and the right of the cross two large water cooled coils are situated producing a constant magnetic field ( $\leq 140 \mathrm{mT}$ ) parallel to the front of the target holder. Collector plates (e.g. Si-wafers) could be mounted to catch macro-particles emitted by the arc. After baking $\left(150^{\circ} \mathrm{C} \ldots\right.$ $250^{\circ} \mathrm{C}$ ) a typical base pressure of $1.5 \times 10^{-7} \mathrm{~Pa}$ was reached. The ignition of the discharge was forced by a $10 \mathrm{kV}$ pulse applied to the additional ignition electrode. The chamber was acting as the anode. A power supply developed for coating experiments was used (500A ... 1.5kA). Larger currents imply a larger number of simultaneous cathode spots leaving the characteristics of the individual spot unchanged. The discharge duration was chosen from $300 \mu$ s to $5 \mathrm{~ms}$.

Samples $(40 \mathrm{~mm} \times 30 \mathrm{~mm} \times 16 \mathrm{~mm}$, graphite coated by $5 \mu \mathrm{m}$ W) from PFCs manufactured for AUG have been mounted as the cathode. Additionally, pieces of pure $\mathrm{W}$ and samples made from graphite (without coating) have been investigated for comparison.

For the optical observation two cameras (a Phantom v7.3 manufactured by Vision Research and an Exilim EX-F1 from CASIO) took pictures through the observation port. For the monitoring of tracks of emitted particles a set up with a side view on the sample was used preferentially.

\section{Experimental results}

For the first few consecutive discharges on a virgin sample of pure $\mathrm{W}$ or W-coated graphite a diffusive radiating front moves over the cathode surface (velocity $\approx 150 \mathrm{~m} / \mathrm{s}$ ). It splits successively into self-avoiding pieces that repel each other and, thereby, covers a large fraction of the surface. Subsequent discharges of the same type tend to occupy the remaining virgin parts of the cathode. The erosion rate is low (e.g. too low to be properly quantified by profilometry). In post mortem investigations the damaged zone constituting the arc track is difficult to detect. After this initial phase the arc discharges show a very different appearance. Now a group of concentrated radiating 
spots is developed moving over the cathode surface. The arc melts the surface locally producing craters that build up a chain constituting the remnant arc track. This track can be detected post mortem and an erosion rate can be estimated. In our experiments the spots moved at a velocity of about $100 \mathrm{~m} / \mathrm{s}$.

For W-coated cathodes the most remarkable difference is the occasional appearance of very bright spots in the course of the discharge that do not move and stay until the discharge ends. Subsequent discharges follow generally different individual tracks but, typically, re-activate some of the former bright spots. This is demonstrated in fig. 1 by plotting the integrated intensity of three selected spots over time on a discharge-by-discharge basis. Only very few new spots are produced mainly on the borders of the established arcing area. However, immobile spots are not habitual for arcing on W, whereas they are a common feature of arcing on pure graphite.

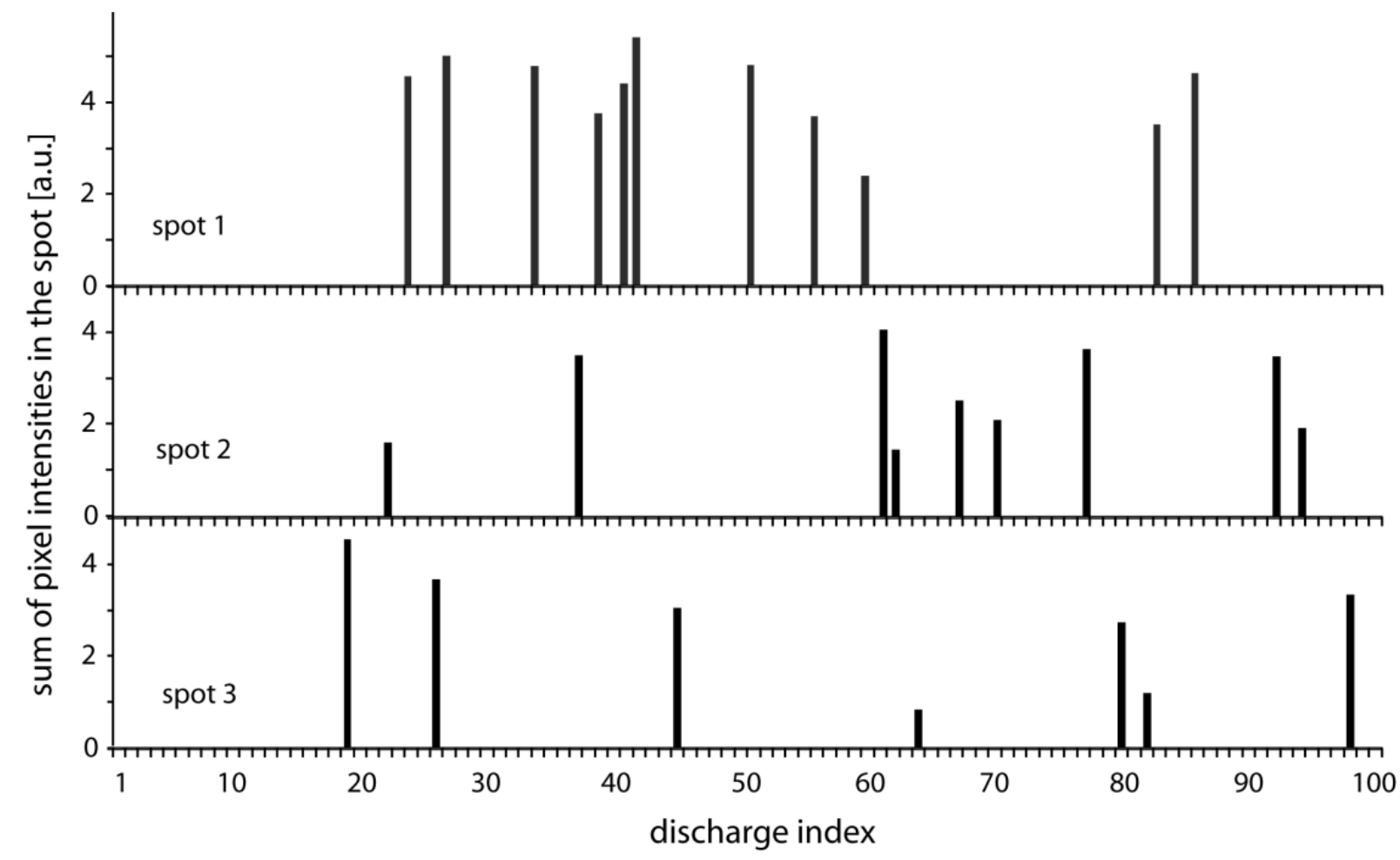

fig. 1: recurrence of three individual bright spots in a series of consecutive discharges 
In between the bright spots, and suggestively connecting them, washed-out radiating areas of much less brightness are seen in the open shutter photographs. They are suspected to be the images of regions occupied by smaller movable spots like the ones that left the remnant craters found on Wcoated graphite cathodes post mortem. The appearance of those craters is comparable to arc craters on bulk W to the greatest possible extend. The distribution of the crater diameters (fig. 2) can be satisfactorily described by a power law (indicating a scale invariance; see also [3]) with an exponent close to -2 .

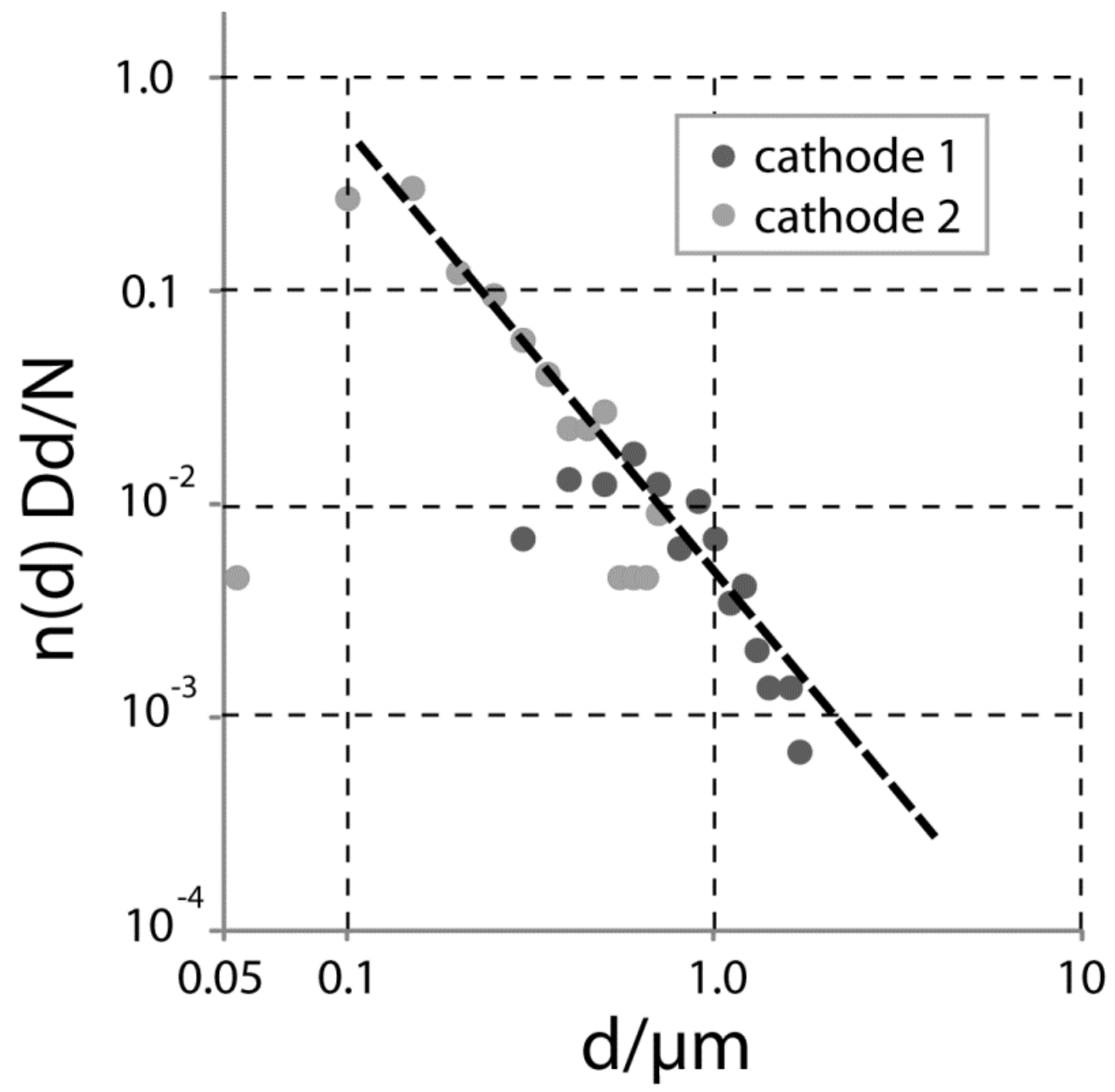

fig. 2: distribution of craters over the diameter $d$ for several sample areas on two different cathodes. 
From depth profiles of craters by cross-sectioning with a focused ion beam an indication for a final breaking through the $W$-coating was identified at the center of a quite large crater $(\varnothing \approx 2.7 \mu \mathrm{m}, \mathrm{fig} .3)$.

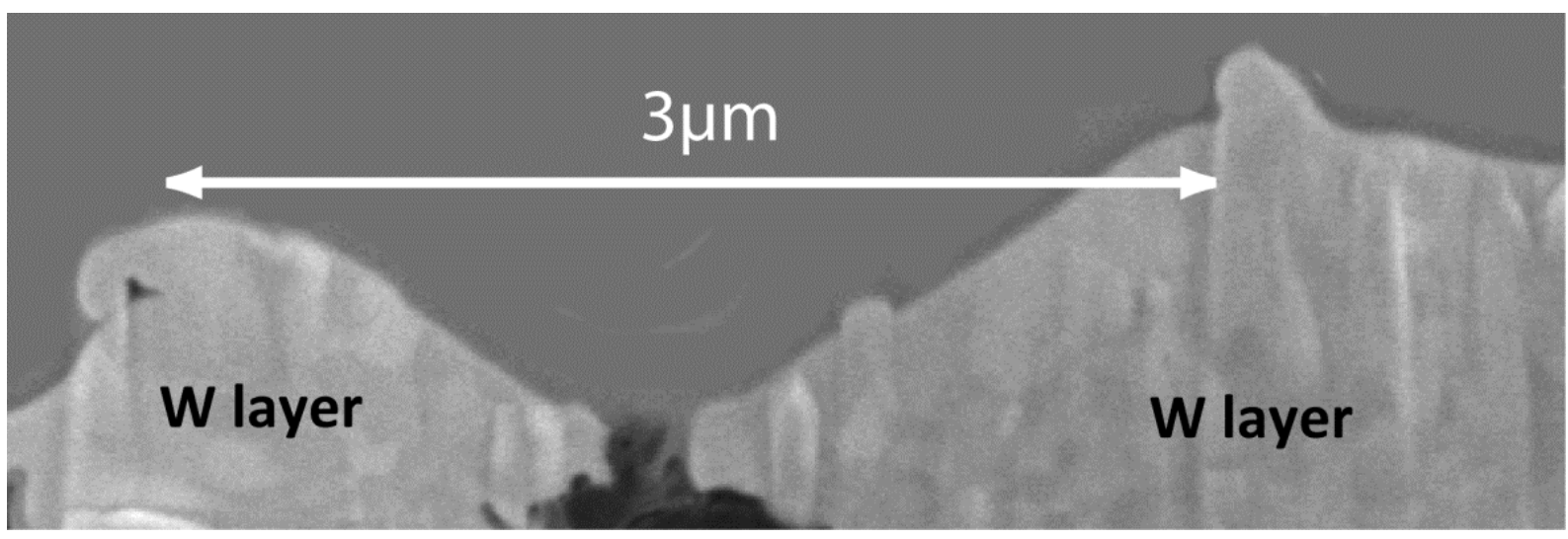

fig. 3: deeper crater showing a cut-through to the graphite substrate.

This implies that the underlying graphite is exposed locally on the sample surface.

Besides the craters described above large holes are found on the surface of coated cathodes as a result of arcing (there were no prior macroscopic damage to the coating). They perforate the $\mathrm{W}$-layer and expose large areas of graphite. The shape of the holes is close to cylindrical and every hole is imbedded in a region scattered with normal arc craters. EDX imaging confirms an almost complete removal of the layer within the hole so that the bottom consists of graphite only. The distribution of hole-diameters is centered at $17 \mu \mathrm{m}(\mathrm{HWHM}$ of $\approx 5 \mu \mathrm{m})$. This implies that the smallest holes identified $(\varnothing \approx 7 \mu \mathrm{m})$ are not much larger than the largest normal craters $(\varnothing \approx 4 \mu \mathrm{m})$. Holes are a local failure of the coating and the majority of the $\mathrm{W}$-layer is still intact (the relative hole area is found be between $1 \%$ and $4 \%)$. The cross-section of a typical hole is shown in fig. 4 and a mechanically obtained radial profile (averaged over the angle) is given in fig. 5 together with the radially integrated volume (dashed line). Both figures demonstrate very clearly, that the erosion process excavating the hole does not stop at the base of the layer (at a depth of $\approx 5 \mu \mathrm{m}$ ) but extends deeply into the graphite substrate. 


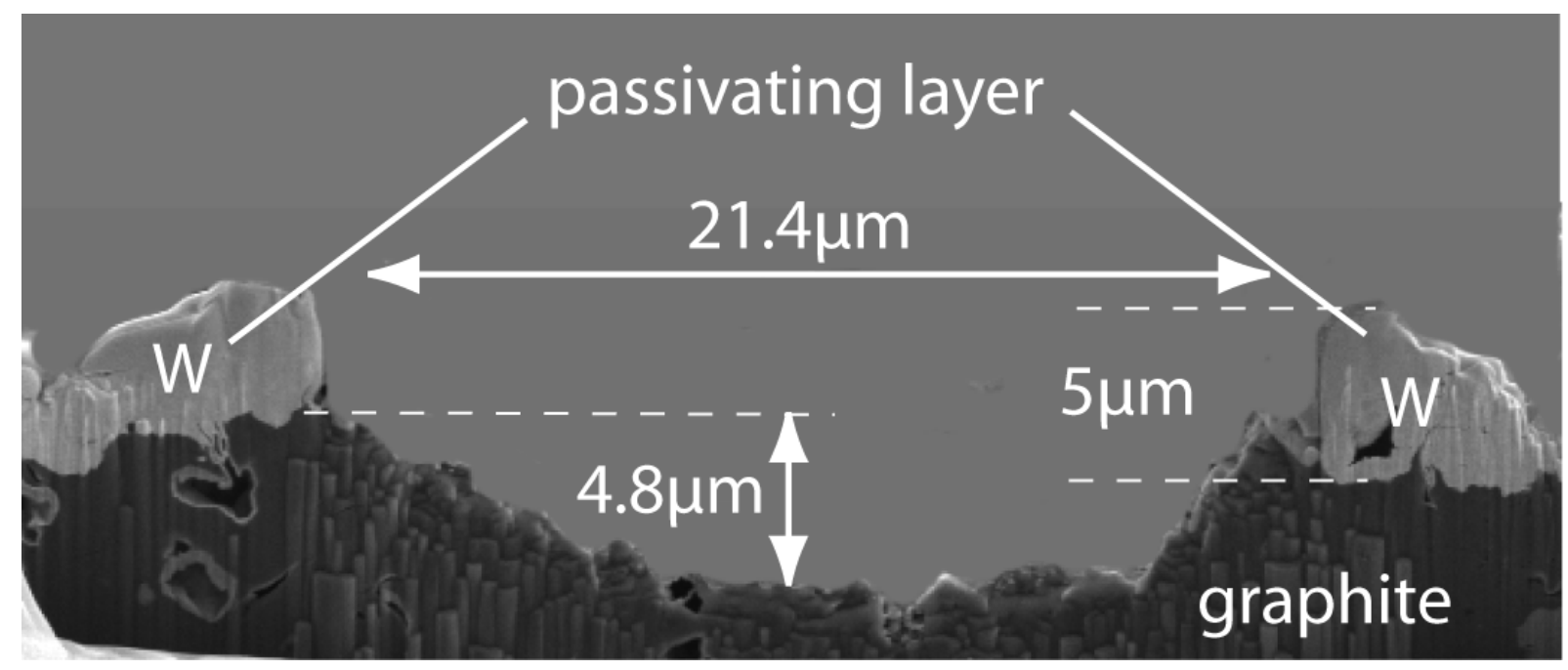

fig. 4: cut through a hole (ion etching technique) demonstrating an erosion reaching deep into the graphite substrate

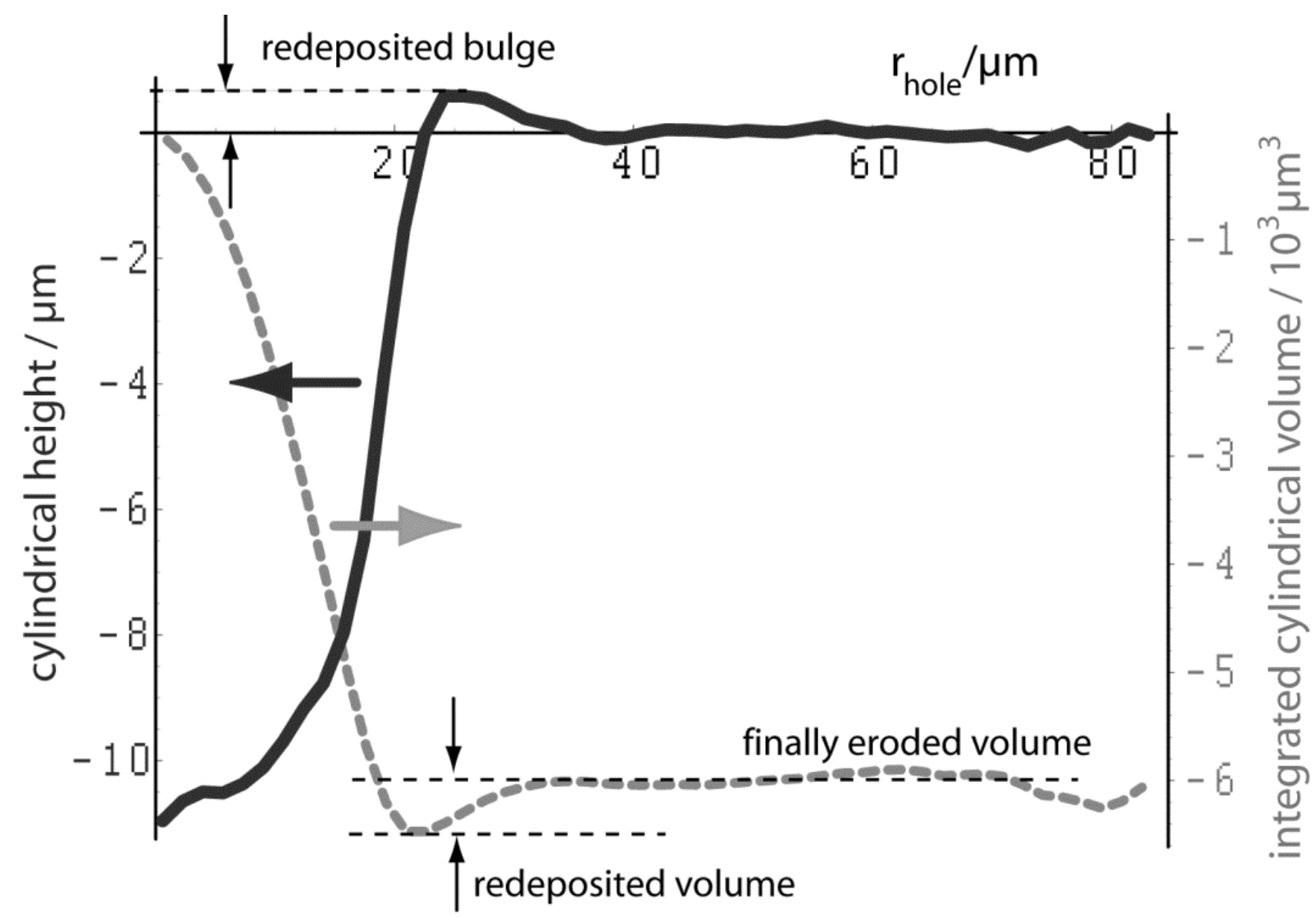

fig. 5 : reconstruction of a radial profile (red) and the related integrated volume (blue, eroded parts count negative) - both based on the assumption of cylindrical symmetry of the hole 
To investigate the relation between the eroded holes and the immobile radiating spots the microscope image of the region containing holes has to be mapped as congruent as possible to the region in the camera frame showing the spots. All examples of such a comparisons proved that every stationary bright spot is related to an excavated hole and vice versa.

Additionally, narrow tracks of fast flying luminous macro-particles ejected from the spots are seen in the open-shutter photographs. Piecewise traces (from multi-frame exposures) can be used to determine the velocities of the macro-particles using an appropriate reproduction scale and the duration of the shutter opening. As a result the velocity distribution of particles can be constructed (fig. 6). It appears to have two distinct contributions (one at $\langle\mathrm{v}\rangle \approx 21 \mathrm{~m} / \mathrm{s}, \Delta v \approx 11 \mathrm{~m} / \mathrm{s}$, and the other at $\langle\mathrm{v}\rangle \approx 77 \mathrm{~m} / \mathrm{s}, \Delta \mathrm{v} \approx 23 \mathrm{~m} / \mathrm{s})$.

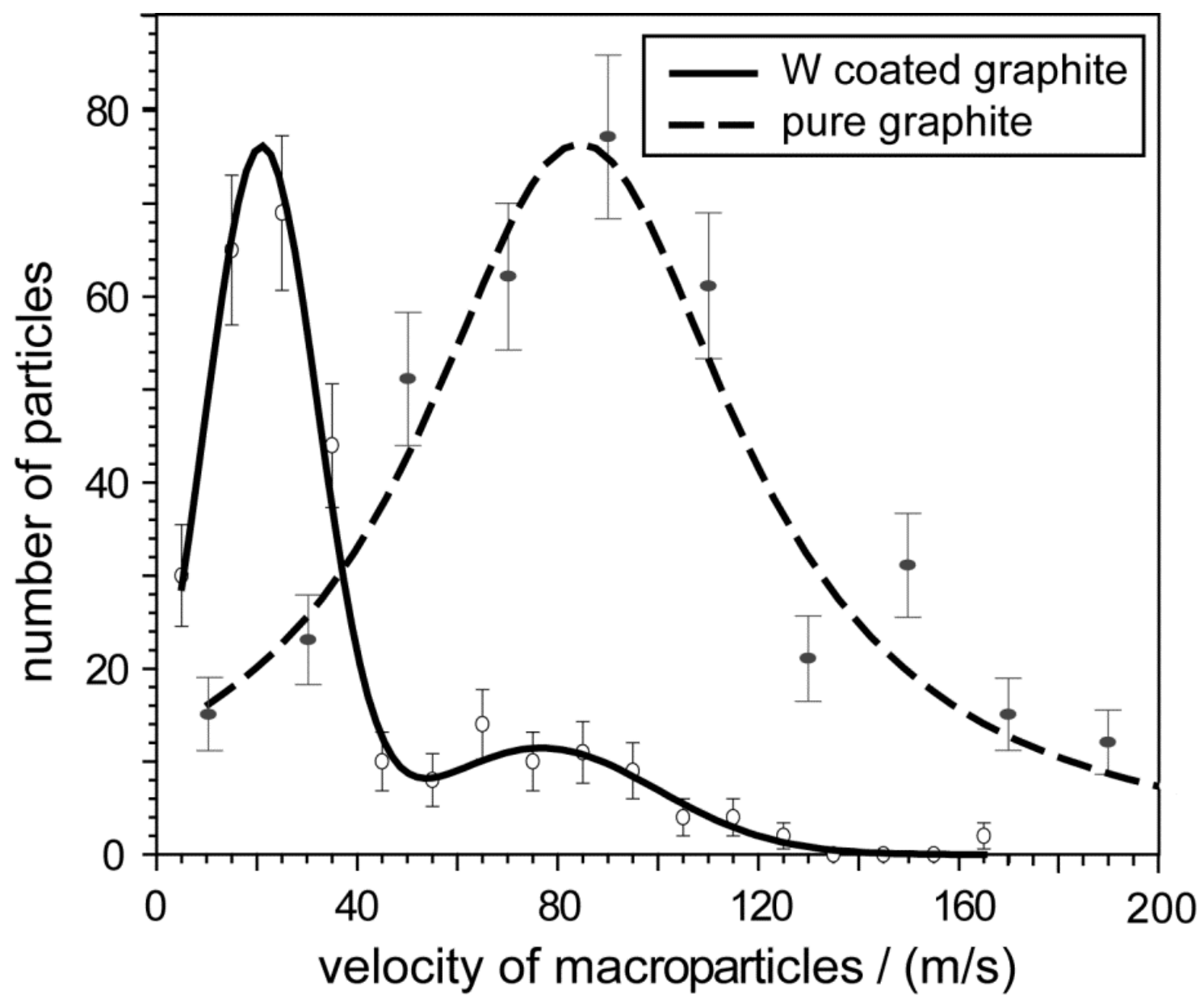


fig. 6 : velocity distribution of particles ejected from a W-coated cathode (solid) clearly showing two distinct components. For comparison the analogous distribution for arcing experiments on a cathode made from pure graphite (dashed) is shown.

To render more specific investigations of the particles possible, dedicated collectors (either Si-wafers or hard disc blanks) have been mounted to the sides of the cathode sample and exposed to discharges. Exploiting the SEM their coordinates, elemental composition, and characteristics of the shape could be recorded. As an outcome fig. 7 shows the diameter distribution of W-particles (restricted to approximately spherical ones showing more than 50wt\% W from EDX) summed up over the whole Si-collector. From the angular distribution of particles it can be clearly stated that essentially all ejection angles are possible (not only flat ejection as occasionally stated in the literature [11]). The processing of this data is ongoing.

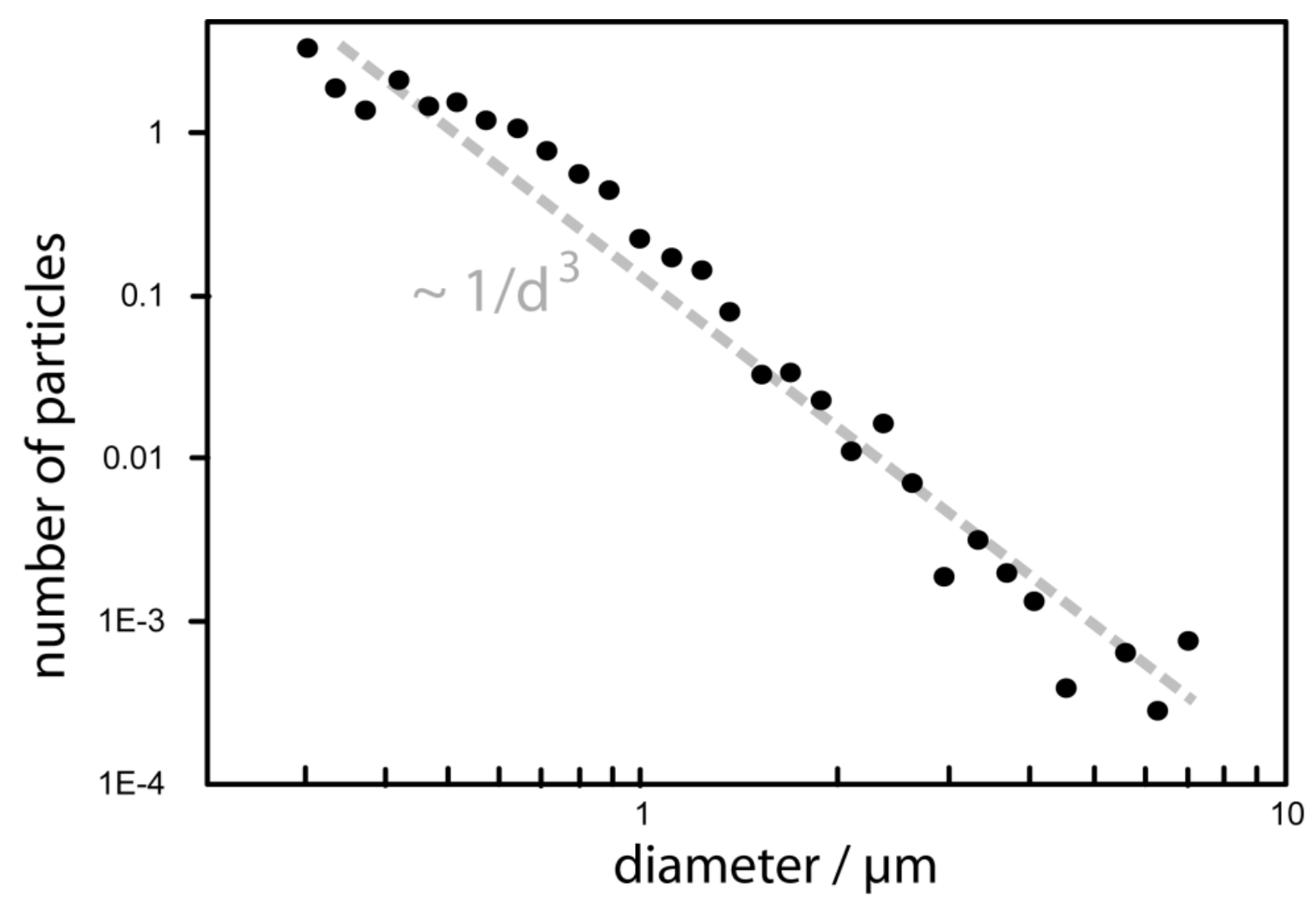

Fig. 7 : diameter distribution of spherical W-particles ejected from a W-coated cathode and collected on a Si-wafer. 


\section{Summary and Discussion}

Besides the typical small craters $(\varnothing \approx 0.2 \ldots 2.0 \mu \mathrm{m})$, arcing on graphite samples covered by a $5 \mu \mathrm{m} W$ layer exhibit large holes $(\varnothing \approx 12 \ldots 22 \mu \mathrm{m})$ perforating the coating thereby breaking the coverage and exposing the underlying graphite. The residence time of an arc at a hole is often comparable to the duration of the discharge and subsequent discharges show a clear tendency to revitalize and expand holes already existing. Considering the fact that the small craters resemble very closely those on bulk $W$ and that the diameters of the largest classical craters $(\approx 2.7 \mu \mathrm{m})$ and the smallest holes $(\approx 6 \mu \mathrm{m})$ on a coated surface are close, it seems plausible to assume that craters expected to populate the large diameter-tail of the distribution $(\varnothing>3 \mu \mathrm{m})$ are degenerated into holes. As a confirmation examples of very large craters were found to exhibit a breakthrough to the graphite bulk at their bottom pointing to an insufficient thickness of the coating. This breakthrough is assumed to be the consequence of a heat build-up at the discontinuity in heat as well as electrical conduction introduced at the interface between W-layer and graphite bulk. Even though the number of holes and their overall area (and, therefore, the erosion rate) is small, they establish an important source of $\mathrm{W}$ and carbon despite the fact that almost the whole surface is still covered by the $\mathrm{W}$-layer. Nevertheless, holes show larger diameters than expected for the corresponding large classical craters, and the W-layer is removed completely throughout the area of a hole. Therefore, the amount of eroded $\mathrm{W}$ is probably larger than it would have been for a much thicker coating where the discontinuity of the interface is out of reach of even the largest craters. Applying the estimated hole fraction $(1 \% \ldots 4 \%)$ to an entire arcing area (where the integral charge transferred by the arcs is known) allows to compare the amount of W eroded in the holes to the amount expected for the transferred charge (relying on erosion rates for $\mathrm{W}$ in the literature [4]). It results that the holes contribute only $\approx 20 \%$ to the total arc erosion and, therefore, it can be stated that they enhance the W erosion but do not dominate it. Depth profiles of individual holes demonstrate that the graphite is also eroded. It can be speculated that a repetitive arcing of the same location on a W-coated graphite PFC caused by dominant ignition locations together with the presence of a strong magnetic field may 
finally create the continuously perforated tracks observed at the baffle tiles of the divertor of AUG [6, 7]. To estimate the overall eroded material in a machine demands a complete overview over the areas showing arc traces. Up to now this has been accomplished only for special groups of PFCs (e.g. in AUG, [7]). Holes are the main sources for the emission of large macro-particles made of $W$ and $C$ having average ejection velocities of $23 \mathrm{~m} / \mathrm{s}$ and $77 \mathrm{~m} / \mathrm{s}$, respectively (as can be concluded from the comparison of the velocity distributions for W-coated with pure graphite). The distribution of the particle diameters can be approximately described by $n(d) \sim 1 / d^{3}$, with $n(d)$ the number of particles having diameters around $d$. This implies that every diameter interval contributes the same amount to the integral particle volume. The distribution of the number of particles over the ejection angle seems to be quite flat. This ensures that macro-particles are also emitted under steep angles (close to the normal of the cathode surface). Consequently, they may pass the scrape-off layer at unfavorable locations and introduce a W (or C)-source into the confined plasma of a fusion device. 


\section{References}

[1] G.M. McCracken, D.H.J. Goodall, Nucl. Fusion 18 (1978) 537

[2] R. Behrisch, J.Nucl.Mater. , 85\&86 (1979), 1047-1061

[3] A. Anders, "Cathodic Arcs- from Fractal Spots to Energetic Condensation", Springer US, 2009

[4] R.L. Boxman, D.M. Sanders, P.J. Martin (Eds.), Handbook of Vacuum Arcs Science and Technology, Material Science and Process Technology Series, Noyes Publications, Park Ridge, New Jersey, USA, 1995

[5] ] R. Behrisch, Contrib.Plasm.Phys. 42 (2002) 431-444

[6] M. Laux, W. Schneider, B. Jüttner, S. Lindig, M. Mayer, M. Balden, I. Beilis, B. Djakov, J. Nucl. Mater. 337-339 (2005) 1019-1023

[7] A. Herrmann, M. Balden, M. Laux, K. Krieger, H.W. Müller, R. Pugno, V. Rohde, ASDEX Upgrade team, J.Nucl.Mater. 390-391 (2009), 747-750

[8] V. Rohde, N. Endstrasser, U.v. Toussaint, M. Balden, T. Lunt, R. Neu, A. Hakola, J. Bucalossi, J.Nucl.Mater. 415 (2011) S46-S50

[9] N. Endstrasser, V. Rohde, M. Balden,P. Humrickhousen, U.v. Toussaint B.J. Braams, H-K. Chung, R. Neu and the ASDEX Upgrade team, Phys. Scr. T145 (2011) 014021

[10] M. Marx, Untersuchung von Vakuumbögen auf Erste-Wand-Materialien, Diplomarbeit (FH), Technische Hochschule Wildau, Fachbereich Ingenieurwesen/Wirtschaftsingenieurwesen, Wildau, 4. April 2011,

Searching: http://www.th-wildau.de/bibliothek/die-digitale-bibliothek-elektronische-medien.html

[11] J.E. Daalder, J. Phys. D: Appl. Phys., 9 (1976) 2379-2395 